\title{
Selective determination of chromium(VI) ions using in-tube electro-membrane extraction followed by flame atomic absorption spectrometry
}

Leila Boutorabi, Maryam Rajabi ${ }^{1}$, Mohammad Bazregar, Alireza Asghari 


\section{Abstract}

In the present work, a novel and efficient method, namely in-tube electro-membrane extraction followed by flame atomic absorption spectrometry (IEME-FAAS), is used for the selective determination of chromium( $\mathrm{VI})$ ions in some environmental samples. In this approach, which is based upon the electro-kinetic migration of ionized compounds, by applying an electrical potential difference, the analyte is extracted from an aqueous sample solution through a supported liquid membrane (SLM) into an acceptor solution. A thin polypropylene (PP) sheet placed inside a tube acts as a support for the membrane solvent used, and $100 \mu \mathrm{L}$ of an aqueous acceptor solution is separated by this solvent from $5.0 \mathrm{~mL}$ of an aqueous donor solution. In order to achieve the best extraction efficiency, the effective parameters involved including the voltage magnitude, SLM solvent, extraction time, and $\mathrm{pH}$ range are optimized. Under the optimized experimental conditions, the IEME-FAAS method provides a good linearity in the range of $10.0-600 \mathrm{ng} \mathrm{mL}^{-1}$, a low limit of detection (3.0 $\mathrm{ng} \mathrm{mL}^{-1}$ ), and good extraction repeatabilities (RSDs below 8.6\%, $n=5$ ). Finally, the developed method is used for the selective determination of chromium(VI) ions in the tap, river, and mineral water samples.

Keywords: In-tube electro-membrane extraction (IEME); Flame atomic absorption spectrometry (FAAS); Selective determination of chromium(VI) ions. 


\section{Introduction}

The toxicity of heavy metals causes these elements to be a threat to the human life and the environment. Hence, determination of trace amounts of these agents in different environmental samples is important, and this has attained a high national and international priority [1]. Furthermore, the impact of detrimental heavy metals on the human health depends significantly on their chemical forms [2-4]. It is well-known that the toxicological as well as the biological properties of these elements are strongly dependent on their chemical forms [5]. While Cr(III) ions are essential for our body and they are a part of our daily diet, $\mathrm{Cr}(\mathrm{VI})$ ions are highly toxic to humans, causing different disorders, and they are classified as a suspected carcinogenic agent [6-9]. For the very same reasons, the focus of a significant portion of analytical chemistry is shifting from the determination of total concentrations towards the development of selective assays of individual chemical species $[1,10,11]$. The considerable progress made in chemical analysis has caused the introduction of fantastic methods such as inductively coupled plasma-atomic emission spectrometry (ICP-AES), ICP-mass spectrometry (ICP-MS), electrothermal-AAS (ET-AAS), and flame atomic absorption spectrometry (FAAS). These methods can easily detect the total amount of chromium but cannot distinguish between the $\mathrm{Cr}(\mathrm{III})$ and $\mathrm{Cr}(\mathrm{VI})$ ions, while the total chromium does not provide sufficient information to understand the toxicity of the samples [12].

The above-mentioned cases well-reflect the key role of sample preparation in sample analysis. In fact, an appropriate sample preparation can increase the applicability of the mentioned methods to the selective determination of analytes like chromium ions. There are some methods such as liquid-liquid extraction (LLE) [13] and solid-phase 
extraction (SPE) [14] that can be used for the selective determination of $\mathrm{Cr}(\mathrm{VI})$ ions. However, these extraction methods are time-consuming and require moderate-to-large amounts of highly expensive and potentially hazardous organic solvents [15]. In the last few years, the research activities have been oriented toward the development of efficient and miniaturized sample pretreatment methods. Solid-phase microextraction (SPME) [16] and liquid-phase microextraction (LPME) [17] have been introduced according to this attitude. Despite its remarkable features, SPME is time-consuming and expensive. Also the sample carry-over can be a great problem in this method [18]. Single-drop microextraction (SDME), dispersive liquid-liquid microextraction (DLLME) [19], hollow fiber-protected liquid-phase microextraction (HF-LPME) [20], and electromembrane extraction (EME) are some of the most popular LPME modes. EME, as a method used for the extraction of different ionizable compounds and biologically active analytes, has been introduced by Pedersen-Bjergaard and co-workers in 2006 [21]. This method is based upon the electro-kinetic migration of ionized compounds, and the driving force in this method is an electrical potential applied over the supported liquid membrane (SLM). For this purpose, one of the electrodes is placed in an aqueous sample solution, while the other one is put in an acceptor aqueous solution inside the lumen of the fiber. In this condition, the ionized target analytes are extracted from the sample solution into SLM and then transported into the acceptor solution. EME can provide excellent sample clean-up and analyte enrichment from complicated samples. The results reported for the utilization of EME have shown that applying an electrical driving force as a green auxiliary energy can be a useful approach in the sample preparation field [22]. Despite these EME advantages, there are some 
constraints on this approach, which have mostly arisen due to its set-up [23]. EME usually suffers from instability problems caused by bubble formation and SLM punctuation. Some studies on EME have shown that by increasing the fiber thickness, the flux of analytes across SLM can be decreased and the mole ratio of the analytes trapped in SLM can be increased [24]. Nevertheless, the most common fiber used has a $600-\mu m$ inner diameter and a 200- $\mu \mathrm{m}$ wall thickness. Also in EME, impregnation of the fiber pores, removal of the organic solvent from the lumen, and sealing the hollow fiber are tedious and can reduce the extraction repeatability [22]. Recently, our team has introduced an efficient, simple, and comfortable method, namely in-tube electromembrane extraction (IEME), to resolve some EME constraints [23]. The basis of IEME and EME is similar, and an excellent purification is simply obtained. Although in EME a hollow fiber is usually used as an inert supporting material, in IEME a thin polypropylene (PP) sheet placed inside a tube acts as a support for the membrane solvent, and a small volume of an aqueous acceptor solution is separated by this solvent from an aqueous donor solution. Thus filling the PP sheet pores with the organic solvent, inserting the sheet in the tube, and the extraction process are very comfortable and repeatable. Besides, IEME is environmentally friendly due to the consumption of a low amount of the organic solvent, and it seems that this extraction unit design can be a proper one for the automation of the method. However, this design somewhat suffers from the formation of bubbles in the extraction process. In fact, in this design, if the cathode and anode are not placed at the ends of the acceptor and donor solutions, the bubbles formed may move around the membrane and disturb the mass transfer. 
In order to resolve this problem, in this work, the design of the acceptor chamber was modified and a cathode chamber was installed at the end of the donor chamber. Hence, the bubbles formed around the electrodes could leave the solutions through these entries. In this work, for the first time, IEME, as a simple, environmentally friendly, and efficient method was modified and used for the selective determination of chromium(VI) ions. Considering the importance of separation of chromium(VI) ions from chromium(III) ions before the selective determination of these analytes by atomic absorption spectrophotometry, it seems that using an applied electrical field can be a unique approach for this purpose. In fact, in aqueous samples, all forms of $\mathrm{Cr}(\mathrm{VI})$ species have a negative charge and all forms of $\mathrm{Cr}(\mathrm{III})$ species have a positive charge. Consequently, in an applied electrical field, the $\operatorname{Cr}(\mathrm{VI})$ species migrate toward the positive electrode and the $\mathrm{Cr}(\mathrm{III})$ species migrate toward the negative electrode.

\section{Experimental}

\subsection{Reagents and solutions}

1-octanol, 2-nitrophenyloctyl ether (NPOE), and di-(2-ethylhexyl) phosphate (DEHP) were all supplied from Fluka (Buchs, Switzerland). Analytical grade $\mathrm{H}_{3} \mathrm{PO}_{4}(85 \%), \mathrm{NaCl}$, $\mathrm{HCl}(37 \%), \quad \operatorname{Cr}\left(\mathrm{NO}_{3}\right)_{3}, \quad \mathrm{~K}_{2} \mathrm{Cr}_{2} \mathrm{O}_{7}, \mathrm{CH}_{3} \mathrm{COONH}_{4}, \quad \mathrm{NaHCO}_{3}, \quad \mathrm{CaCl}_{2}, \mathrm{MgN}_{2} \mathrm{O}_{6} \cdot 6 \mathrm{H}_{2} \mathrm{O}$, $\mathrm{AlN}_{3} \mathrm{O}_{9} .9 \mathrm{H}_{2} \mathrm{O}, \mathrm{CaCO}_{3}$, and $\mathrm{NaOH}$ were all obtained from Merck (Darmstadt, Germany). Ammonia solution (25\%) was purchased from Merck-Schuchardt (Munich, Germany). The stock $\mathrm{Cr}(\mathrm{VI})$ solution (1000 $\mathrm{mg} \mathrm{L}^{-1}$ ) was prepared from $\mathrm{K}_{2} \mathrm{Cr}_{2} \mathrm{O}_{7}$. The working standard solutions were prepared by the stepwise dilution of the stock solution just before use. All the glassware used was kept at least overnight in 10\% (v/v) nitric acid solution, 
and subsequently, rinsed with doubly distilled water before use. The other chemicals used were of high analytical grade.

\subsection{Sample preparation}

Mineral water was suplied from a local market. River water (from Shahmirzad, Iran) and tap water (from Semnan University) were collected in amber glass containers and maintained in the dark at $4 \circ \mathrm{C}$ until analysis. No filtration or further treatment was applied to any of the samples before extraction.

\subsection{Instruments}

Platinum wires of 0.5-mm diameter, obtained from Pars Platin (Tehran, Iran), were used as the anode and cathode. These electrodes were connected to a power supply with a tunable voltage in the range of 0-600 V (supplied from Mobtaker Ariayi, J. MAJ Co., Zanjan, Iran). The sheetholder used was poly(methyl methacrylate), which was made in our laboratory. Accurel PP 1E (R/P) flat membrane (Membrana, Wuppertal, Germany) with a thickness of $100 \mu \mathrm{m}$, an average pore size of $100 \mathrm{~nm}$, and a porosity of $69 \%$ was used as the supporting membrane. All the measurements were performed using an Agilent 200 Series AA (model 240 AA) flame atomic absorption spectrometer (USA) including air-acetylene flame and simultaneous four hollowcathode lamps. The instrumental parameters were adjusted as follow: a Cr wavelength of 357.9

$\mathrm{nm}$ (slit width, $0.2 \mathrm{~nm}$ ) and a lamp current of $10.0 \mathrm{~mA}$. The acceptor phase was taken and injected into the FAAS nebulizer using a home-made micro-sample introduction system consisting of a Teflon funnel and an Eppendorf pipette (Fig. 1), and the peak areas were measured. The $\mathrm{pH}$ values for the solutions were measured using a PHS-3BW model $\mathrm{pH}$ meter (Bell, Italy). 


\subsection{Procedure}

The IEME set-up is shown in Fig. 2. The donor chamber was a tube. The hole in one of the pieces of the two-piece sheet-holder acted as the acceptor chamber and the other piece was connected to the donor chamber. The donor and acceptor volumes were $5.0 \mathrm{~mL}$ and $105 \mu \mathrm{L}$, respectively. At first, the propylene sheet was placed on one of the holes of the two-piece sheetholder. Using a $5-\mu \mathrm{L}$ GC syringe ITO (Fuji, Japan), $1.0 \mu \mathrm{L}$ of the membrane solvent was put on the sheet and the solvent was spread to impregnate the pores of the sheet by the side of the syringe. Subsequently, the other piece of the holder was placed on the sheet, and the two pieces were connected to each other using four bolts. The donor and acceptor chambers were filled with the sample and acceptor solutions, respectively. The cathode and anode were fixed to the sample and acceptor solutions, respectively. Then a voltage of $250 \mathrm{~V}$ was applied for $25 \mathrm{~min}$. After the extraction, $100 \mu \mathrm{L}$ of the acceptor phase was collected and analyzed by the micro-sampling flame atomic absorption spectrometry (MS-FAAS) technique to determine the metal ion concentrations. The absorbance signals were measured as peak areas with a $3 \mathrm{~s}$ integration time.

\subsection{Calculation of enrichment factor and extraction recovery}

The enrichment factor (EF) for the target analytes was calculated according to the following equation:

where $\mathrm{C}_{\mathrm{a}, \text { final }}$ is the final concentration of the analyte in the acceptor solution and $\mathrm{C}_{\mathrm{s} \text {,initial }}$ is the initial analyte concentration in the sample (donor) solution. 
Also the percent extraction recovery (ER \%) for the IEME procedure was calculated according to the following equation:

where $V_{s}$ is the sample volume, $V_{a}$ is the acceptor solution volume, and $n_{s, \text { initial }}$ and $n_{a, \text { final }}$ are the number of moles of the analyte originally present in the sample solution and the number of moles of the analyte finally collected in the acceptor solution, respectively.

\section{Results and discussion}

The extraction efficiency and mass transfer in EME has previously been discussed from a theoretical viewpoint [24]. This study showed that the steady-state flux of the th cationic analyte $\left(\mathrm{J}_{\mathrm{i}}\right)$ across SLM may be calculated by the following equation:

where $D_{i}$ is the diffusion coefficient of the analyte, $h$ is the thickness of the membrane, $\mathrm{C}_{\text {in }}$ is the analyte concentration at the SLM/sample interface, $\mathrm{C}_{\mathrm{io}}$ is the analyte concentration at the acceptor/SLM interface, $x$ is the ratio of the total ionic concentration in the sample solution to that in the acceptor solution that is defined as the ion balance (the sum of the ions in the donor solution divided by the sum of the ions in the acceptor solution), and $v$ is a dimensionless driving force defined by: 
where $z_{i}$ is the charge of the analyte, $e$ is the elementary charge, $\Delta \varnothing$ is the electrical potential across SLM, $\mathrm{k}$ is the Boltzmann's constant, and T is the absolute temperature.

On the basis of this theory, the SLM thickness is an important parameter, affecting the extraction efficiency, and by increasing the membrane thickness, the flux of analytes across SLM can be decreased. On this basis, to improve the flux of analytes across SLM, the conventional hollow fibers with a thickness of $200 \mu \mathrm{m}$ were replaced with a flat membrane of $100-\mu m$ thickness. Also in order to obtain the best extraction performance, the parameters affecting the extraction process including the SLM solvent, extraction time, sample solution $\mathrm{pH}$, acceptor solution $\mathrm{pH}$, and applied voltage were studied and optimized.

\subsection{Composition of SLM}

Based on Eq. 3, the flux of analytes is affected by the nature of SLM, which determines the diffusion coefficients of the target substances $\left(D_{i}\right)$. Hence, the chemical nature of the supported liquid membrane is highly critical for the success of EME. There are some requirements for a solvent to be used as SLM in this method. Particularly, in EME, the sample solution (SLM) and the acceptor solution should complete an electrical circuit. Thus the solvent should have a sufficient electrical conductivity to allow the electro-kinetic migration of compounds across SLM into the acceptor solution. Based on these considerations and other experiences, common organic solvents including 1octanol, NPOE, and a mixture of 80-90\% NPOE and 10-20\% di-(2-ethylhexyl)phosphate (DEHP) were evaluated. As it can be seen in Fig. 3, 1-octanol had the highest extraction efficiency compared to the other tested solvents. Some studies have revealed that one of the main parameters that should be considered for selection of 
SLM is the number of $\mathrm{H}$-acceptor or $\mathrm{H}$-donor functionalities in an organic solvent [25, 26]. Based on these studies, a proper liquid membrane for extraction of anionic analytes is the one that possesses a relatively high number of $\mathrm{H}$-donor functionalities. Accordingly, long-chain alcohols are desirable alternatives for this aim. Therefore, 1octanol was selected for further examinations.

\subsection{Effect of $\mathrm{pH}$}

IEME is based upon the electro-kinetic migration of the ionized compounds. In order to pass the analytes through an applied electric field, it is necessary to change them to their ionizable forms. The existing forms of the chromium species in solution depend on the $\mathrm{pH}$ value for the sample solution, which have a key role in the efficiency and selectivity of the extraction. Depending on the solution $\mathrm{pH}$, the $\mathrm{Cr}(\mathrm{VI})$ species may be in the form of dichromate $\left(\mathrm{Cr}_{2} \mathrm{O}_{7}{ }^{2-}\right)$, hydrochromate $\left(\mathrm{HCrO}_{4}^{-}\right)$or chromate $\left(\mathrm{CrO}_{4}{ }^{2-}\right)$. All forms of $\mathrm{Cr}(\mathrm{VI})$ species have a negative charge. In contrast, all forms of $\mathrm{Cr}(\mathrm{III})$ species have a positive charge. Thus depending on the solution $\mathrm{pH}$, these species may take the form of hydrated trivalent chromium, $\mathrm{Cr}\left(\mathrm{H}_{2} \mathrm{O}\right)_{6}{ }^{3+}$, chromium hydroxide, $\mathrm{Cr}(\mathrm{OH})$ $\left(\mathrm{H}_{2} \mathrm{O}\right)_{5}{ }^{2+}$ or $\mathrm{Cr}(\mathrm{OH})_{2}\left(\mathrm{H}_{2} \mathrm{O}\right)^{4+}{ }^{[12]}$. This fact provides an opportunity for an efficient separation and a selective extraction of the $\mathrm{Cr}(\mathrm{III})$ and $\mathrm{Cr}(\mathrm{VI})$ ions using an applied electric field, and it was the basis of the current study. In order to investigate the effect of the sample solution $\mathrm{pH}$ on the extraction process, it was varied in the range of 2-10

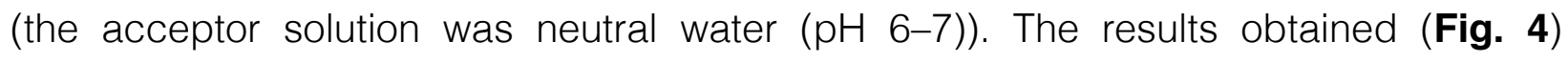
showed that the analytes could be extracted at all $\mathrm{pH}$ values by applying a potential difference. However, the best extraction results were achieved at $\mathrm{pH}$ 6. It seems that the $\mathrm{Cr}(\mathrm{VI})$ ions are in the anionic form as $\mathrm{HCrO}_{4}-$ in $\mathrm{pH}$ 6, and this form could be easily 
extracted into SLM. Also by increasing the $\mathrm{pH}$ value, the concentration of hydroxide ions can be increased. Since these ions have a similar charge as the analytes, they can contribute to the migration and lead to a reduction in the migration of the analytes at a fixed time. On the other hand, the presence of other ions (such as $\mathrm{H}^{+}$) in acidic $\mathrm{pH}$ values could affect the thickness of the double layer, and this can affect the extraction efficiency. In separate experiments, the $\mathrm{pH}$ value for the acceptor solution was varied

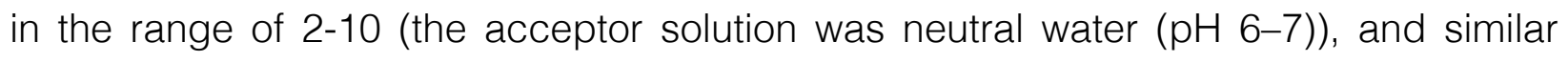
results were obtained. The results obtained showed that neutral water $(\mathrm{pH} \mathrm{6-7)}$ was the best choice for the selective extraction of $\mathrm{Cr}(\mathrm{VI})$ ions from aqueous samples.

\subsection{Applied voltage}

According to the EME theoretical model [24], the main driving force for the migration of analytes across the liquid membrane can be provided by an applied electric field, and the strength of the electric field is dependent on the applied voltage. This model predicts that the flux of analytes can be improved by increasing the potential difference $(\Delta \varnothing)$ across SLM. Hence, the effect of an applied voltage on the extraction efficiency was investigated. Fig. 5 shows that the extraction recovery increased as the voltage was increased from 150 to $250 \mathrm{~V}$, and by a further increase in the applied potential, the recovery remained almost unchanged. Thus an applied voltage of $250 \mathrm{~V}$ was chosen for the subsequent analyses.

\subsection{Extraction time}

The extraction time is another parameter that can affect the flux of analytes in EME. Increasing the extraction time can directly increase the flux of ions and thus increase the extraction recovery. To investigate the effect of this parameter on the extraction 
efficiency at constant extraction conditions, the extraction efficiency was studied as a function of time. In Fig. 6, the recovery is plotted against the extraction time. As it can be seen, the extraction efficiency increased with time until 25 min, whereas, for longer extraction times, the recovery was constant. In fact, the system entered the steadystate conditions and the gain in recovery became minimal. Hence, an extraction time of 25 min was selected as the optimum one.

\section{Effect of interfering ions}

The presence of co-existing ions may result in interferences with both the extraction and detection processes. While utilization of a sample preparation method with a high sample clean-up can be a beneficial solution for decreasing the interferences with the detection process, these ions can act as a competitor for the target analyte and reduce the extraction efficiency. To evaluate the selectivity of the proposed method for the determination of trace levels of $\mathrm{Cr}(\mathrm{VI})$ ions, and also to investigate the effect of the presence of the common co-existing ions on the extraction efficiency of the target analyte, some experiments were designed in the presence of these ions. The interference was considered to occur when the measured recoveries varied more than $\pm 5 \%$ relative to those for the target ions. For this purpose, $5.0 \mathrm{~mL}$ of the sample solution containing $100 \mathrm{ng} \mathrm{mL}^{-1}$ of $\mathrm{Cr}(\mathrm{VI})$ ions with various amounts of the interfering ions were treated according to the proposed method. One of the distinguishing features of the proposed method is that it provides a high sample clean-up. In fact, the method is based upon the electro-kinetic migration of the ionized compounds by the application of an electrical potential difference. Hence, many interfering species in the detection system that have positive charges migrate toward the negative electrode, 
whereas the target analyte migrates toward the positive electrode. On the other hand, many species with negative charges migrate toward the positive electrode, although they cannot pass through the membrane. However, due to the competition of these anions with the target analyte in the extraction process, the extraction efficiency can reduce. The results obtained, summarized in Table 1, demonstrate that thousand-fold excesses of the analyte ion have no effect on the preconcentration and determination of the $\mathrm{Cr}(\mathrm{VI})$ ions. According to these results, it can be concluded that the proposed method provides a good extraction efficiency and selectivity for the $\mathrm{Cr}(\mathrm{VI})$ ions in the presence of the mentioned co-existing ions.

\section{Method evaluation}

Following the experiments reported above, the analyte under investigation was extracted under the optimal experimental conditions to investigate the performance of the system. For this purpose, the linearity, repeatability, and detection limit were investigated by utilizing the standard solutions of the target analyte in deionized water. The calibration plot had a linear response in the range of $10-600 \mathrm{ng} \mathrm{mL}^{-1}$ with the determination coefficient $\left(r^{2}\right)$ of 0.997 . The detection limit was evaluated as the concentration corresponding to three times the standard deviation of the blank signal, and was found to be $3 \mathrm{ng} \mathrm{mL}-1$ for the target analyte. The repeatability of the peak areas was studied for five replicate extractions, and deionized water was spiked at the $50.0 \mathrm{ng} \mathrm{mL}^{-1}$ level. The relative standard deviations (RSDs) for the analyte were lower than $8.6 \%$ on the basis of the peak areas. The percentage extraction recovery (ER\%) and the enrichment factor (EF) were calculated using the equations mentioned in

section 2.5 (Table 2). There are a number of methods that were used for the extraction 
of $\mathrm{Cr}(\mathrm{VI})$ ions from various samples. Some of these methods were compared with IEME (Table 3). Comparison of IEME with these methods showed that by the consumption of a low organic solvent (1.0 $\mu \mathrm{L}$ of 1 -octanol), the method provided comparable results with other methods. Also applying the electrical driving force as a green auxiliary energy and the purification of the three-phase methods caused a proper clean-up.

\section{Application of IEME to real samples}

To examine the possibility of matrix effects and investigate the applicability of the developed method to the analysis of field samples, the method was used to determine the analyte under investigation in the three studied water samples, i.e. the river, tap, and mineral water samples. No filtration or further treatment was applied to any of the samples before extraction. In order to investigate the matrix effects, all the real samples were spiked with proper amounts of the analyte, and the recoveries were subsequently calculated. The results obtained showed that the different matrices used for the river, tap, and wastewater samples had little effects on the extraction efficiency, and they confirmed the existence of the target analyte in all the studied samples. Also the proposed method showed high relative recoveries for all the real samples from 97 to $106 \%$, which ensured the accuracy of the amount of analytes detected in the non-spiked real samples (Table 4).

\section{Conclusion}

Depending on the $\mathrm{pH}$, all forms of the $\operatorname{Cr}(\mathrm{VI})$ and $\operatorname{Cr}(\mathrm{III})$ species had negative and positive charges in aqueous samples, respectively. This fact provides an opportunity for an efficient separation of $\mathrm{Cr}(\mathrm{III})$ ions from $\mathrm{Cr}(\mathrm{VI})$ ions using an applied electric field, 
and this was the basis of the current study. In this work, in-tube electro-membrane extraction (IEME), as a comfortable and efficient method, was applied to the selective extraction of chromium( $\mathrm{VI})$ ions from the environmental samples. This method is based upon the electro-kinetic migration of ionized compounds, and by migration of the $\mathrm{Cr}(\mathrm{VI})$ and $\operatorname{Cr}(\mathrm{III})$ ions to the anode and cathode, respectively, the $\operatorname{Cr}(\mathrm{VI})$ species (as carcinogenic agents) were separated from the $\mathrm{Cr}(\mathrm{III})$ species in aqueous samples. In order to achieve the best extraction efficiency, the effective parameters involved were optimized, and the developed method was successfully used for the selective determination of chromium( $\mathrm{VI})$ ions in the tap, river, and mineral water samples. In contrast to EME, IEME is very simple, so that filling the PP sheet pores with the organic solvent, inserting the sheet in the tube, and the extraction process are very comfortable and repeatable, and the results obtained show that IEME is a good choice for the selective extraction of the $\mathrm{Cr}(\mathrm{VI})$ species. Besides, it is environmentally friendly due to a low organic solvent consumption.

\section{Acknowledgment}

The authors would like to thank the Iran National Science Foundation (INSF- 93038916) for the financial support of this work. 


\section{References}

[1] S.C. Nielsen, S. Stürup, H. Spliid, E.H. Hansen, Selective flow injection analysis of ultratrace amounts of $\mathrm{Cr}(\mathrm{VI})$, preconcentration of it by solvent extraction, and determination by electrothermal atomic absorption spectrometry (ETAAS), Talanta 49 (1999) 1027-1044.

[2] A. Kot, J. Namiesńik, The role of speciation in analytical chemistry, Trends Anal. Chem, 19 (2000) 69-79.

[3] M. Kim, J. Stripeikis, M. Tudino, Flow injection solid phase extraction electrothermal atomic absorption spectrometry for the determination of $\mathrm{Cr}(\mathrm{VI})$ by selective separation and preconcentration on a lab-made hybrid mesoporous solid microcolumn, Spectrochim. Acta B 64 (2009) 500-505.

[4] Á. Béni, R. Karosi, J. Posta, Speciation of hexavalent chromium in waters by liquid-liquid extraction and GFAAS determination, Microchem. J. 85 (2007) 103-108.

[5] F. Laborda, M.P. Górriz, E. Bolea, J.R. Castillo, Mathematical correction for polyatomic interferences in the speciation of chromium by liquid chromatography-inductively coupled plasma quadrupole mass spectrometry, Spectrochim. Acta B 61 (2006) 433-437.

[6] I. Turyan, D. Mandler, Selective Determination of $\mathrm{Cr}(\mathrm{VI})$ by a Self-Assembled MonolayerBased Electrode, Anal. Chem. 69 (1997) 894-897.

[7] M. Korolczuk, M. Grabarczyk, Application of Voltammetric Method of Total Chromium Determination in the Presence of Cupferron for Selective Determination of $\mathrm{Cr}(\mathrm{VI})$ in Water Samples, Microchem. J. 62 (1999) 311-315.

[8] R. Karosi, V. Andruch, J. Posta, J. Balogh, Separation of chromium (VI) using complexation and its determination with GFAAS, Microchem. J. 82 (2006) 61-65. 
[9] Y. Cui, X. Chang, X. Zhu, H. Luo, Z. Hu, X. Zou, Q. He, Chemically modified silica gel with p-dimethylaminobenzaldehyde for selective solid-phase extraction and preconcentration of Cr(III), Cu(II), Ni(II), Pb(II) and Zn(II) by ICP-OES, Microchem. J. 87 (2007) 20-26.

[10] Z. Bahadir, V.N. Bulut, M. Hidalgo, M. Soylak, E. Marguí, Determination of trace amounts of hexavalent chromium in drinking waters by dispersive microsolid-phase extraction using modified multiwalled carbon nanotubes combined with total reflection X-ray fluorescence spectrometry, Spectrochim. Acta B 107 (2015) 170-177.

[11] M. Ohata, N. Matsubayashi, Determination of hexavalent chromium in plastic certified reference materials by X-ray absorption fine structure analysis, Spectrochim. Acta B 93 (2014) 14-19.

[12] M. Safari, S. Nojavan, S.S.H. Davarani, A. Morteza-Najarian, Speciation of chromium in environmental samples by dual electromembrane extraction system followed by high performance liquid chromatography, Anal. Chim. Acta 789 (2013) 58-64.

[13] S. Kalidhasan, M. Ganesh, S. Sricharan, N. Rajesh, Extractive separation and determination of chromium in tannery effluents and electroplating waste water using tribenzylamine as the extractant, J. Hazard. Mater. 165 (2009) 886-892.

[14] T.-H. Ding, H.-H. Lin, C.-W. Whang, Determination of chromium(III) in water by solidphase microextraction with a polyimide-coated fiber and gas chromatography-flame photometric detection, J. Chromatogr. A 1062 (2005) 49-55.

[15] M. Rajabi, M. Bazregar, Y. Yamini, A. Asghari, B. Ebrahimpour, Electrophoretic micropreconcentration of ionizable compounds as a green approach in sample preparation, Microchem. J. 125 (2016) 124-129. 
[16] C.L. Arthur, J. Pawliszyn, Solid phase microextraction with thermal desorption using fused silica optical fibers, Anal. Chem. 62 (1990) 2145-2148.

[17] Y. He, H.K. Lee, Liquid-Phase Microextraction in a Single Drop of Organic Solvent by Using a Conventional Microsyringe, Anal. Chem. 69 (1997) 4634-4640.

[18] M. Bazregar, M. Rajabi, Y. Yamini, A. Asghari, M. Hemmati, Tandem air-agitated liquidliquid microextraction as an efficient method for determination of acidic drugs in complicated matrices, Anal. Chim. Acta 917 (2016) 44-52.

[19] S. Berijani, Y. Assadi, M. Anbia, M.-R. Milani Hosseini, E. Aghaee, Dispersive liquidliquid microextraction combined with gas chromatography-flame photometric detection: Very simple, rapid and sensitive method for the determination of organophosphorus pesticides in water, J. Chromatogr. A 1123 (2006) 1-9.

[20] S. Pedersen-Bjergaard, K.E. Rasmussen, Liquid-Liquid-Liquid Microextraction for Sample Preparation of Biological Fluids Prior to Capillary Electrophoresis, Anal. Chem. 71 (1999) 2650-2656.

[21] S. Pedersen-Bjergaard, K.E. Rasmussen, Electrokinetic migration across artificial liquid membranes: New concept for rapid sample preparation of biological fluids, J. Chromatogr. A 1109 (2006) 183-190.

[22] Y. Yamini, S. Seidi, M. Rezazadeh, Electrical field-induced extraction and separation techniques: Promising trends in analytical chemistry - A review, Anal. Chim. Acta 814 (2014) $1-22$. 
[23] M. Bazregar, M. Rajabi, Y. Yamini, A. Asghari, Y. Abdossalami asl, In-tube electromembrane extraction with a sub-microliter organic solvent consumption as an efficient technique for synthetic food dyes determination in foodstuff samples, J. Chromatogr. A 1410 (2015) 35-43. [24] A. Gjelstad, K.E. Rasmussen, S. Pedersen-Bjergaard, Simulation of flux during electromembrane extraction based on the Nernst-Planck equation, J. Chromatogr. A 1174 (2007) 104-111.

[25] M. Balchen, L. Reubsaet, S. Pedersen-Bjergaard, Electromembrane extraction of peptides, J. Chromatogr. A 1194 (2008) 143-149.

[26] Y. Yamini, S. Seidi, M. Rezazadeh, Electrical field-induced extraction and separation techniques: Promising trends in analytical chemistry - A review, Anal. Chim. Acta 814 (2014) $1-22$.

[27] H.F. Maltez, E. Carasek, Chromium speciation and preconcentration using zirconium(IV) and zirconium(IV) phosphate chemically immobilized onto silica gel surface using a flow system and F AAS, Talanta 65 (2005) 537-542.

[28] I. Narin, A. Kars, M. Soylak, A novel solid phase extraction procedure on Amberlite XAD-1180 for speciation of $\mathrm{Cr}(\mathrm{III}), \mathrm{Cr}(\mathrm{VI})$ and total chromium in environmental and pharmaceutical samples, J. Hazard. Mater. 150 (2008) 453-458.

[29] M.V. Balarama Krishna, K. Chandrasekaran, S.V. Rao, D. Karunasagar, J. Arunachalam, Speciation of $\mathrm{Cr}(\mathrm{III})$ and $\mathrm{Cr}(\mathrm{VI})$ in waters using immobilized moss and determination by ICPMS and FAAS, Talanta, 65 (2005) 135-143. 
[30] L.-L. Wang, J.-Q. Wang, Z.-X. Zheng, P. Xiao, Cloud point extraction combined with highperformance liquid chromatography for speciation of chromium(III) and chromium(VI) in environmental sediment samples, J. Hazard. Mater. 177 (2010) 114-118.

[31] A. Tunçeli, A.R. Türker, Speciation of $\mathrm{Cr}(\mathrm{III})$ and $\mathrm{Cr}(\mathrm{VI})$ in water after preconcentration of its 1,5-diphenylcarbazone complex on amberlite XAD-16 resin and determination by FAAS, Talanta 57 (2002) 1199-1204.

\section{Figure captions}

Fig. 1. Photograph of home-made micro-sample introduction system of flame atomic absorption spectrometry.

Fig. 2. Schematic diagram and photograph of IEME. Conditions: sample solution volume, $5.0 \mathrm{~mL}$; acceptor volume, $105 \mu \mathrm{L}$; extraction voltage, $250 \mathrm{~V}$; time, $25 \mathrm{~min}$; SLM, 1octanol.

Fig. 3. Effect of composition of SLM on extraction efficiency. Conditions: sample solution volume, $5.0 \mathrm{~mL}$ of $100 \mathrm{ng} \mathrm{mL}^{-1}$ of analyte in deionized water; acceptor volume, $105 \mu \mathrm{L}$ (deionized water); extraction time, 45 min; applied voltage, $300 \mathrm{~V}$. Error bars were obtained based on three replicates.

Fig. 4. Effect of donor $\mathrm{pH}$ on extraction efficiency. Conditions: sample solution volume, $5.0 \mathrm{~mL}$ of $100 \mathrm{ng} \mathrm{mL}^{-1}$ of analyte in deionized water; acceptor volume, $105 \mu \mathrm{L}$ (deionized water); SLM, 
1-octanol; applied voltage, $300 \mathrm{~V}$; extraction time, $45 \mathrm{~min}$. Error bars were obtained based on three replicates.

Fig. 5. Effect of applied voltage on extraction efficiency. Conditions: sample solution volume, $5.0 \mathrm{~mL}$ of $100 \mathrm{ng} \mathrm{mL} \mathrm{m}^{-1}$ of analyte in deionized water; acceptor volume, $105 \mu \mathrm{L}$ (deionized water); extraction time, 45 min; SLM, 1-octanol. Error bars were obtained based on three replicates.

Fig. 6. Effect of extraction time on extraction efficiency. Conditions: sample solution volume, $5.0 \mathrm{~mL}$ of $100 \mathrm{ng} \mathrm{mL}^{-1}$ of analyte in deionized water; acceptor volume, $105 \mu \mathrm{L}$ (deionized water); SLM, 1-octanol; applied voltage, 250 V. Error bars were obtained based on three replicates. 
Table 1. Effects of potentially interfering ions on extraction recovery of target ions.

\begin{tabular}{|c|c|c|c|}
\hline \multirow{2}{*}{ Ion } & \multirow{2}{*}{ Mass ratio } & \multirow{2}{*}{ Added as } & \multirow{2}{*}{$\frac{\text { Recovery (\%) }}{\mathrm{Cr}^{6+}}$} \\
\hline & & & \\
\hline $\mathrm{Na}^{+}$ & 2000 & $\mathrm{NaCl}$ & 98.3 \\
\hline $\mathrm{K}^{+}$ & 2000 & $\mathrm{KCl}$ & 97.5 \\
\hline $\mathrm{Ca}^{2+}$ & 200 & $\mathrm{CaCO}_{3}$ & 102.2 \\
\hline $\mathrm{Mg}^{2+}$ & 200 & $\mathrm{Mg}\left(\mathrm{NO}_{3}\right)_{2} \cdot 6 \mathrm{H}_{2} \mathrm{O}$ & 96.8 \\
\hline $\mathrm{Al}^{3+}$ & 100 & $\mathrm{Al}\left(\mathrm{NO}_{3}\right)_{3 .} .9 \mathrm{H}_{2} \mathrm{O}$ & 99.7 \\
\hline $\mathrm{Cl}^{-}$ & 2000 & $\mathrm{CaCl}_{2}$ & 95.5 \\
\hline $\mathrm{Cr}^{3+}$ & 2000 & $\mathrm{Cr}\left(\mathrm{NO}_{3}\right)_{3}$ & 99.1 \\
\hline $\mathrm{CH}_{3} \mathrm{COO}-$ & 1000 & $\mathrm{CH}_{3} \mathrm{COONH}_{4}$ & 98.1 \\
\hline $\mathrm{HCO}_{3}^{-}$ & 500 & $\mathrm{NaHCO}_{3}$ & 101.3 \\
\hline $\mathrm{NO}_{3}^{-}$ & 2000 & $\mathrm{NaNO}_{3}$ & 100.6 \\
\hline
\end{tabular}


Table 2. Figures of merit for proposed method for target analyte.

\begin{tabular}{|c|c|c|c|c|c|c|}
\hline Analyte & LOD & LDR & $\mathrm{R}^{2}$ & $\begin{array}{c}\text { RSD\% }(n=5) \\
\text { Intra-day (Inter-day) }\end{array}$ & $\mathrm{ER} \%$ & $\mathrm{EF}$ \\
\hline $\mathrm{Cr}^{6+}$ & 3.0 & $10-600$ & 0.997 & $7.4(8.6)$ & 46 & 23 \\
\hline
\end{tabular}


Table 3. Comparison between IEME and other microextraction techniques for determination of $\mathrm{Cr}(\mathrm{VI})$.

\begin{tabular}{|c|c|c|c|c|c|}
\hline Analytical method & Sample volume (mL) & EF & $\begin{array}{c}\mathrm{LOD}(\mathrm{ng} \\
\left.\mathrm{mL}^{-1}\right)\end{array}$ & $\begin{array}{c}\mathrm{RSD} \\
\%\end{array}$ & $\begin{array}{c}\text { Referenc } \\
\mathrm{e}\end{array}$ \\
\hline SPE-FAAS & 15 & 24 & 2.3 & 3.0 & [27] \\
\hline SPE-FAAS & 150 & 75 & 7.7 & 5.7 & [28] \\
\hline SPE-ICP-MS & 20 & 20 & 0.15 & $<10$ & [29] \\
\hline CPE-HPLC & 10 & 40 & 3.5 & 2.7 & {$[30]$} \\
\hline SPE-FAAS & 250 & 25 & 45 & - & [31] \\
\hline DEME-HPLC & 2.1 & 33 & 2.8 & $<13.7$ & {$[12]$} \\
\hline IEME-FAAS & 5.0 & 23 & 3.0 & 8.6 & $\begin{array}{l}\text { This } \\
\text { work }\end{array}$ \\
\hline
\end{tabular}


Table 4. Analysis of real samples under optimal experimental conditions.

\begin{tabular}{|c|c|c|c|c|}
\hline Analyte & & Mineral water & River water & Tap water \\
\hline \multirow{5}{*}{$\mathrm{Cr}^{6+}$} & Initial & 377 & 275 & 426 \\
\hline & Added & 100.0 & 100.0 & 100.0 \\
\hline & Found & 106.3 & 96.6 & 97.4 \\
\hline & $\mathrm{RR} \%$ & 106 & 97 & 97 \\
\hline & $\operatorname{RSD} \%(n=3)$ & 6.9 & 7.0 & 4.7 \\
\hline
\end{tabular}

